\title{
CRM na administração pública: desenvolvimento e validação de uma Escala de Relacionamento com o Cidadão (ERCi)
}

\author{
Gisela Demo \\ Universidade de Brasília (UnB) / Departamento de Administração / Programa de \\ Pós-Graduação em Administração \\ Brasília / DF - Brasil \\ Renata Pessôa \\ Universidade de Brasília (UnB) / Departamento de Administração \\ Brasília / DF - Brasil
}

\begin{abstract}
As empresas utilizam a gestão de relacionamento com o cliente ou Customer Relationship Management (CRM) para estabelecer relacionamentos de longo prazo, mantendo seus clientes satisfeitos e fiéis. Neste contexto, o Citizen Relationship Management (CiRM) surge no setor público como estratégia para aprimorar o atendimento ao cidadão e incentivar a cidadania. Considerando a lacuna da literatura sobre o tema, o objetivo deste estudo multimétodo foi validar um instrumento para avaliar a percepção dos cidadãos quanto às iniciativas de CiRM na administração pública. A principal contribuição deste trabalho consistiu na validação de um instrumento, em versões completa e reduzida, com índices psicométricos muito confiáveis, que pode ser utilizado como ferramenta diagnóstica pelos gestores públicos para promover uma gestão profícua do relacionamento com os cidadãos.
\end{abstract}

Palavras-chave: marketing de relacionamento; administração pública; cidadão; CiRM; desenvolvimento e validação de escala.

CRM en la administración pública: desarrollo y validación de una Escala de Relacionamiento con los Ciudadanos (ERCi)

Las empresas utilizan la gestión de relacionamiento con el cliente o CustomerRelationship Management (CRM) para establecer relacionamientos de largo plazo, manteniendo sus clientes satisfechos y fieles. En este contexto, Citizen Relationship Management (CiRM) aparece en el sector público como estrategia para mejorar el atendimiento al ciudadano e incentivar la ciudadanía. Considerando la brecha en el tema, el objetivo de este estudio de tipo multi-método fue validar un instrumento para evaluar la percepción de los ciudadanos en cuanto a las iniciativas de CiRM en la administración pública. La contribución principal de este trabajo consistió en la validación de un instrumento, en la versión com-

DOI: http://dx.doi.org/10.1590/0034-7612131226

(cc) BY-NC

Artigo recebido em 25 fev. 2014 e aceito em 28 jan. 2015.

Rev. Adm. Pública - Rio de Janeiro 49(3):677-697, maio/jun. 2015 
pleta y reducida, con índices psicométricos muy confiables, que puede utilizarse como herramienta diagnóstica por los gestores públicos para promover una gestión provechosa de relacionamiento con los ciudadanos.

Palabras Clave: marketing de relacionamiento; administración pública; ciudadano; CiRM; desarrollo y validación de escala.

CRM in the public management: development and validation of a Citizen Relationship Scale (CiRS) Companies use the Customer Relationship Management (CRM) to establish long-term relationships with their customers in order to keep them satisfied and loyal. In this context, Citizen Relationship Management (CiRM) emerges in the public sector as a strategy to improve citizens' service and to encourage citizenship as well. Considering the gap in the literature on the subject, the aim of this multi-method study was to validate an instrument to assess the perception of citizens regarding CiRM initiatives in public management. The main contribution of this work is the validation of an instrument, in both complete and reduced versions, with very reliable psychometric rates, which can be used as a diagnostic tool by public managers to promote an effective relationship management with citizens.

Keywords: relationship marketing; public management; citizen; CiRM; scale development and validation.

\section{Introdução}

Ao longo do tempo, o cliente assumiu diferentes papéis dentro do contexto organizacional. À época da Revolução Industrial, o cliente era somente mais um elemento para o alcance dos lucros. Com o passar dos anos e com o aumento da concorrência, as empresas privadas perceberam que para ter sucesso era preciso ter foco no cliente. Dessa forma, foi compreendido que não é suficiente somente conquistá-los, mas sim mantê-los. Então, na busca por estabelecer um relacionamento duradouro e por manter clientes satisfeitos e fiéis, as empresas fazem uso da chamada Gestão de Relacionamento com o Cliente (Customer Relationship Management - CRM) ou simplesmente Marketing de Relacionamento (Demo e Rozzett, 2013; Kotler e Keller, 2012).

A utilização de diferentes e inovadoras práticas de gestão pública transformou o modo com que o governo se relaciona com o cidadão e, por isso, já é comum ouvir os administradores públicos utilizando o termo "cliente" quando tratam das empresas com as quais seus órgãos ou departamentos se relacionam (Batista, 2011). Cada cidadão e relacionamento exigem uma forma diferenciada de tratamento (Ribeiro, 2011). A partir dessa consciência e da necessidade de conhecer melhor quem são os clientes e quais as suas demandas, as entidades públicas, em constante contato com o cidadão, têm se esforçado para implementar em seus órgãos o CRM. "O CRM no setor público tem buscado diminuir custos operacionais nas instituições, gerenciar as reclamações e demandas dos cidadãos e diminuir o prazo de atendimento" (Demo e Ponte, 2008:206). Dessa forma, tem-se que o CRM no setor público, denominado Citizen Relationship Management — CiRM (Gestão de Relacionamento com o Cidadão), é tão importante quanto o é para a esfera privada (Batista, 2011). 
Fazendo nova comparação da relevância do tema marketing de relacionamento para o setor privado e para o setor público, é possível observar que existe uma consolidação de estudos do assunto na área privada. Na perspectiva da área pública ocorre o oposto. Conforme Ferreira e colaboradores (2012), apesar de o marketing ter ganho relevância na administração pública, os estudos sobre marketing nas organizações públicas são iniciais, configurando uma importante lacuna na literatura. A revisão bibliométrica realizada pelas autoras no período entre 1997 e 2008 em periódicos nacionais da área de administração desvelou apenas 14 estudos sobre marketing na perspectiva cidadão-consumidor. Tais estudos abordaram aspectos epistemológicos e a efetividade dessa perspectiva.

Especificamente sobre CiRM, realizada em agosto de 2013, não foram localizados estudos publicados nos periódicos de administração em âmbito nacional no período que completa a revisão de Ferreira e colaboradores (2012), a saber, 2008 a 2013. Outrossim, não foi encontrado estudo de desenvolvimento e validação de escalas que permitam avaliar a efetividade de iniciativas de CRM da perspectiva dos cidadãos.

Por conseguinte, o objetivo precípuo deste trabalho foi desenvolver e validar um instrumento para avaliar a percepção dos cidadãos quanto às iniciativas de CiRM em órgãos e empresas públicas. Ademais, foram analisados os resultados referentes à percepção dos cidadãos acerca das iniciativas de CiRM com relação aos aspectos do atendimento, dos canais de relacionamento e da orientação voltada para o próprio cidadão.

O lócus de pesquisa escolhido foi o Superior Tribunal de Justiça (STJ), um órgão do Poder Judiciário, uma vez que o interesse recente pela gestão no Poder Judiciário tem sido revelado pelo aumento das pesquisas nesse âmbito. Em linhas gerais, tais estudos destacaram que a gestão judiciária atual no Brasil tem privilegiado a lógica gerencial com foco na eficácia e nos objetivos estratégicos do poder e não na lógica fiscal, predominantemente economicista (Sena, Silva e Luquini, 2012), o que foi corroborado pelo aumento efetivo da eficiência relativa dos Tribunais de Justiça estadual do Brasil (Nogueira et al., 2012). Não obstante, embora eficiência e celeridade tenham sido as dimensões de desempenho mais abordadas na gestão judicial, o tema ainda é pouco explorado na área de administração pública, constituindo uma lacuna na literatura e levantando a necessidade de estudos futuros desenvolverem modelos de avaliação mais complexos, privilegiando a explicação dos resultados, mais do que sua descrição (Gomes e Guimarães, 2013).

Entendendo a administração como uma ciência essencialmente aplicada, este estudo buscou contribuir de maneira teórico-metodológica e empírica. Teórico-metodológica na tentativa de contribuir para o preenchimento das lacunas na literatura supracitadas e de conduzir estudos relacionais nas áreas de administração pública e marketing. Para tanto, fez uso de métodos qualitativos para o desenvolvimento da escala e de métodos quantitativos para sua validação. Assim, resultou em uma escala com possibilidade de ser utilizada em duas versões, uma completa e outra reduzida. De maneira empírica, as duas versões da escala podem ser adaptadas para os diversos órgãos da administração pública federal, estadual e municipal e ser utilizadas como ferramenta de auxílio pelos gestores no diagnóstico dos aspectos conside- 
rados relevantes na percepção dos cidadãos sobre as iniciativas de CiRM e para uma gestão profícua do relacionamento com os cidadãos.

\section{Referencial teórico}

É importante considerar, nos estudos organizacionais considerando o setor privado, a perspectiva da competitividade. Junto com a globalização e as novas tecnologias, a competitividade é imperativa, resumindo, em sua essência, a busca incessante das organizações por alternativas de diferenciação competitiva (Demo, 2014). Neste contexto, para Mishra e Mishra (2009), o marketing de relacionamento ajuda as empresas a gerenciar de maneira efetiva as interações com os consumidores para melhor atendê-los e estabelecer relacionamentos de longo prazo com eles.

Conforme Grönroos (1994), Sheth e Parvatiyar (2002) e Payne (2006), marketing de relacionamento representa uma mudança de paradigma dos conceitos de marketing, defendendo uma mudança na orientação do marketing transacional para o marketing relacional, em que clientes são bem atendidos e suas necessidades são satisfeitas.

Na visão de Payne (2006), o CRM provê oportunidades para utilizar informações, conhecer melhor os clientes, oferecer valor por meio de ofertas customizadas e desenvolver relacionamentos duradouros. É então necessário que a empresa possua processos, operações e pessoas integradas para que a essência do marketing possa ser a filosofia que norteia todo o negócio. Essa visão confirma a ideia holística do marketing de relacionamento, em que há integração entre todas as partes da organização.

Nesse contexto, o CRM deve ser visto como uma filosofia de negócio, implementada de maneira holística e baseada em processos, que visa criar, desenvolver e aprimorar o relacionamento com os clientes e não como uma simples ferramenta ou software de tecnologia da informação (Payne, 2006). Na visão do autor, o CRM, para ser bem-sucedido, precisa estar imbuído de visão estratégica através do desenvolvimento de relacionamentos com clientes estratégicos, unindo o potencial da tecnologia da informação (TI) às estratégias de marketing de relacionamento que resultarão no estabelecimento de relacionamentos lucrativos de longo prazo.

A produção recente sobre CRM em artigos internacionais traz estudos como os de Ernst e colaboradores (2011) e Iglesias, Sauquet e Montaña (2011), constatando que o CRM atingiu uma maturidade estratégica e influencia todo o ciclo de vida de um produto, constituindo profícuo diferencial competitivo para as organizações por otimizar sua eficiência e resultados como quer que sejam medidos.

Quanto às revisões da literatura sobre CRM, foi considerado marco o primeiro artigo de Ngai (2005), que concluiu pelo vigor da pesquisa acadêmica sobre marketing de relacionamento e interrogou sobre a baixa percentagem de trabalhos relacionados à privacidade em CRM, vaticinando que o setor continuaria a apresentar um crescimento significante nos próximos anos. As revisões mais recentes de Ngai, Xiu e Chau (2009), Wahlberg e colaboradores 
(2009), Demo e colaboradores (2011), Gupta e Sahu (2012), Benouakrim e El Kandoussi (2013), Sojan, Raphy e Thomas (2014) e Faria e colaboradores (2014) confirmaram as expectativas de Ngai (2005), atestando a maturidade no campo da pesquisa científica em CRM.

Outras conclusões desses estudos apontam a predominância de pesquisa de CRM em grandes empresas em detrimento de médias e pequenas empresas, a associação do conceito de CRM a mera ferramenta tecnológica bem como sua implementação como responsabilidade da área de tecnologia da informação e, ainda, a prevalência de estudos com foco no mercado consumidor (B2C) no Brasil, enquanto os estudos internacionais privilegiam o mercado corporativo (B2B). Ademais, parece haver carência de medidas específicas de CRM para o mercado B2C.

Dessarte, Rozzett e Demo (2010), Demo e Rozzett (2013) e Demo (2014) conduziram estudos no Brasil e nos Estados Unidos para desenvolver e validar uma escala para os clientes pessoa física, contemplando o mercado B2C com o objetivo de avaliar a percepção dos clientes quanto aos seus relacionamentos com as empresas em geral. Tais trabalhos serviram de base para o desenvolvimento da Escala de Relacionamento com o Cidadão proposta na presente pesquisa. Em seus estudos, as autoras encontraram, como principal indicador de um CRM efetivo, o reconhecimento da importância do cliente. Posteriormente, Demo e Rozzett (2013) defenderam como importantes indicadores o tratamento respeitoso aos clientes e a recomendação dos serviços a amigos e familiares.

A mudança de paradigma de uma abordagem transacional do marketing para uma abordagem relacional trouxe consigo a possibilidade de estender os pressupostos do CRM para as organizações públicas (Fulla, 2007). Para entender como o CRM chegou ao campo da gestão pública é preciso compreender também algumas fases da administração pública, sua evolução e em que medida o conceito de cidadão pode se aproximar do conceito de cliente.

A primeira fase da administração pública é chamada de patrimonialista. As principais características dessa fase são o desenvolvimento da administração com foco na manutenção do poder tradicional e uma relação de fragilidade com a sociedade (Motta, 2007). A segunda fase da administração pública, denominada burocrática, foi adotada para substituir a patrimonialista. Era preciso fazer uma distinção entre o público e o privado e a separação entre o político e o administrador público (Bresser-Pereira, 1996). O foco estava em garantir o poder do Estado e, como consequência, perde-se a noção de servir à sociedade (Mare, 1995). Outras agravantes foram lentidão dos serviços, altos custos e a não garantia de boa qualidade dos serviços (Bresser-Pereira, 1996).

Contudo, a pouca ou nenhuma orientação para as demandas do cidadão começou a ser percebida no final do século XX, já que à época as funções do Estado eram reduzidas e restringiam-se basicamente a garantir os contratos e as propriedades, a administração da justiça e manutenção da ordem (Mare, 1995). Já no início dos anos 1970, tem-se o surgimento da Nova Gestão Pública, que coloca em destaque questões como promoção da equidade, proatividade do Estado e aumento da qualidade e do número de serviços oferecidos como forma de melhorar a eficiência (Aragão, 1997). 
A nova administração pública é baseada na visão gerencialista e para atingir seus objetivos adota novas tecnologias em busca da modernização e passa a adaptar modelos de gestão da iniciativa privada para a esfera pública. É a partir dessa visão que tenta captar quais as novas tendências da opinião pública, entre as quais irão destacar-se os controles dos gastos e a demanda pela melhora na qualidade dos serviços (Abrucio, 1997). Dessa forma, os avanços trazidos pela administração de empresas por meio das ideias de descentralização e de flexibilização irão influenciar bastante a administração pública (Bresser-Pereira, 1996).

Mais uma vez a administração pública evolui e surge o Public Service Orientation (PSO) ou o Serviço Público Orientado (Abrucio, 1997). O serviço público orientado para o cidadão teve como fundamento a descentralização para promoção das políticas públicas de modo igualitário. Além disso, trouxe consigo a percepção de que a relação com o cidadão é complexa por este não ser, apenas, um consumidor de serviços, uma vez que possui direitos e deveres (Marini, 2003).

Nesse panorama, a sociedade está mais exigente em termos de direitos, qualidade de serviços e bom atendimento. Ademais, pretende-se a promoção da democracia por meio de ações voltadas para o atendimento das necessidades dos cidadãos (Gerzon e Müller, 2009), panorama que serviu de base para se entender o cidadão como um cliente.

No que tange à extensão do uso do termo cliente para os cidadãos, Peci e colaboradores (2008) alertam que no contexto da Nova Administração Pública, ou New Public Management, tais conceitos se confundem sob um enfoque distorcido, defendendo que uma reforma na administração pública deve focar os direitos inerentes à cidadania. Nesse sentido, Fleury (2005:458) propõe que "o papel da política pública tem sido crucial na expansão da cidadania e na construção de uma sociedade mais inclusiva”, ou seja, a cidadania manifesta-se com integração e sociabilidade, não devendo ser guiada por fatores mercadológicos.

Não obstante, Peci e colaboradores (2008) argumentam que a associação entre mercado e sociedade, cliente e cidadão é possível, uma vez que a própria New Public Management propõe uma relação de prestação de serviços públicos entre Estado e sociedade, onde se fazem presentes práticas de mercado tais quais foco na qualidade e demanda, porém a associação à lógica privada não pode se sobrepor à pública, exercendo pressão na agenda pública e perdendo o foco em políticas preponderantes de justiça social, por exemplo. Assim, a acepção do cidadão como cliente precisa ser utilizada com parcimônia.

Ao estudar a adequabilidade do CRM tendo como foco o cidadão e os aspectos do CRM relacionados à responsabilização e confiança no governo e sua efetividade, Fulla (2007) conclui que, com o CRM, canais de contato são criados com os cidadãos. Diversos autores sublinham a importância de existirem diferentes canais de atendimento ao cidadão, sendo exemplos de práticas comuns de CiRM as centrais de atendimento, as ouvidorias e os portais governamentais (Leite e Rezende, 2010; Schellong e Langeberg, 2007).

Demo e Ponte (2008) também elencam as diversas possibilidades de se estreitar o relacionamento com os cidadãos e unificar a prestação de serviços apontando bem-sucedidos exemplos brasileiros, quais sejam, Sistema Único de Saúde, sistema eletrônico de declaração de imposto de renda, urna eletrônica, Na Hora, Poupatempo etc. Essas interações per- 
mitem aos cidadãos exercitar sua cidadania ao monitorar o próprio desempenho de ações e medidas governamentais, o que repercute sobre sua satisfação e, em última análise, sua confiança no governo.

Além disso, Fulla (2007) sugere que, com o CRM, governos em geral podem monitorar e avaliar seus esforços para responder aos problemas dos cidadãos, contribuindo assim para sua efetividade geral. E, por fim, ao consolidar os pontos de entrada de pedidos, o governo pode reduzir as redundâncias e retrabalhos e coordenar melhor o uso dos recursos, melhorando sua eficiência e imagem perante a sociedade. Nesse sentido, Duque, Varajão e Filipe (2011), ao estudarem a implementação de sistemas de CiRM em municípios portugueses, destacaram a importância de se avaliar a satisfação dos usuários com os serviços prestados.

Partindo desses pressupostos, no âmbito do serviço público, entende-se que o CRM busca a união de informações dispersas sobre os cidadãos para melhor compreender suas necessidades e demandas, permitindo melhoria na qualidade das decisões, aumento da qualidade dos serviços e personalização do atendimento (Xavier e Gouveia, 2004). Assim, surge a proposta do Citizen Relationship Management (CiRM), ou Gestão de Relacionamento com o Cidadão, definido como uma estratégia que, apoiada pela tecnologia e com amplo foco no cidadão, objetiva manter e melhorar os relacionamentos e ainda incentivar a cidadania (Schellong, 2005).

O CRM parte de princípios como customização (desde produtos até de informações), integração (entre canais de comunicação e até reengenharia de processos) e identificação de clientes estratégicos (Schellong, 2005). Portanto, esses também serão os princípios que nortearão a filosofia do CiRM (Xavier e Gouveia, 2004). A principal diferença entre o CRM e o CiRM estará no fato de que o segundo tem como objetivos distintos: melhorar a orientação para o cidadão, aprimorar a prestação de contas e influenciar uma mudança na relação entre governo e cidadão (Schellong e Langenberg, 2007). Dessa forma, percebe-se que muitos princípios do CRM não são específicos do setor privado e podem ser adaptados para o CiRM à esfera pública.

Xavier, Gouveia e Gouveia (2003) já alertavam para o fato de que o cidadão e o cliente são a mesma pessoa, a qual assume papéis diferentes em função de suas necessidades e relacionamentos com o Estado e com as empresas. Evidencia-se também que o CiRM é muito mais complexo do que o CRM, posto que o relacionamento do cidadão com o governo e vice-versa assumem diferentes formas e modalidades em função do ciclo de vida do cidadão e em função da efetivação de políticas públicas, por parte do governo.

De maneira ideal, o CiRM deve, portanto, reunir, padronizar a coleta e o tratamento de todas as informações, iniciando com aquelas chamadas cadastrais, dispersas por diferentes "serviços", "secretarias", "ministérios" etc., ao longo da vida do cidadão. Isso implica que as diferentes esferas de governo, municipal, estadual e federal, também possam interagir entre si de modo a minimizar o retrabalho e a duplicação de esforços, a fim de garantir maior qualidade na tomada de decisões por parte do governo e personalização máxima do atendimento ao cidadão (Xavier e Gouveia, 2004). Segundo os autores, a pretensão do CiRM deve sempre voltar-se a conhecer mais e melhor o cidadão, com vistas à satisfação de suas necessidades e 
à garantia da oferta de níveis de serviços iguais ou superiores aos ofertados pelas empresas e, nesse sentido, elas devem investir na capacitação de seus funcionários para que estejam aptos a atender as demandas dos cidadãos de maneira rápida e efetiva.

Nessa linha, Morgan e Hunt (1994) defendem a relevância de se investir em uma equipe atenciosa e prestativa que esteja atenta às sugestões, dúvidas e reclamações dos clientes, no caso do CRM, ou cidadãos, no caso do CiRM. A partir daí, conforme os autores, será estabelecida uma relação de comprometimento e confiança entre as partes.

Nesse sentido, é preciso que as instituições governamentais percebam a importância do foco no cidadão no sentido de se modernizarem e reformularem seus processos de trabalhos, e que universalizem a oferta de serviços para reduzir custos, personalizar o atendimento e oferecer mais informações com maior rapidez (Xavier e Gouveia, 2004).

Por conseguinte, com o entendimento dos princípios básicos do CRM, as organizações públicas perceberão que é necessária não somente a inserção de tecnologia, pois é preciso observar as especificidades de cada organização para um CiRM efetivo. Além disso, é necessário que a instituição esteja disposta a realizar uma mudança cultural e de orientação, baseada na colaboração entre os governos, na adoção de multicanais de comunicação, na reengenharia dos processos e serviços públicos e, mormente, no foco no cidadão (Schellong, 2005). Na mesma linha, conforme Schellong (2008), enquanto conceito multifacetado, que ultrapassa a simples redução tecnológica, o CiRM é melhor entendido como filosofia gerencial baseada na confiança e na aceitação de que os cidadãos devem ter seus desejos e necessidades atendidos com rapidez, eficácia e equidade pelos governos.

\section{Método}

O presente estudo caracteriza-se como de campo, descritivo e instrumental, de corte transversal e natureza multimétodo, uma vez que fez uso das abordagens qualitativas e quantitativas.

O lócus de pesquisa escolhido foi o Superior Tribunal de Justiça (STJ), situado em Brasília (DF), que se apresenta como o tribunal da cidadania em seus canais oficiais de comunicação, e por possuir diversas iniciativas de CiRM. O STJ possui a Central de Atendimento ao Cidadão (CAC), criada para centralizar os serviços mais demandados pelo público do tribunal. O cidadão pode verificar o processo de qualquer lugar, mas se quiser aprofundar alguma questão também pode se dirigir até o STJ. Além disso, possui uma Ouvidoria-Geral para que os cidadãos possam fazer as suas manifestações e conta ainda com uma Seção de Apoio aos Advogados com uma infraestrutura (computadores, telefones, equipe de atendimento) adequada, inclusive, para o atendimento de portadores com necessidades especiais.

Na parte qualitativa, foram entrevistadas seis pessoas (gestores e executores do CiRM no STJ) em agosto de 2013 e foi utilizado um roteiro de entrevista semiestruturada com seis questões baseadas na literatura de CiRM. As perguntas foram: 1) Qual o seu entendimento sobre CiRM? A sua compreensão se aproxima mais de uma filosofia de negócios ou de uma ferramenta tecnológica? 2) Quais os motivos que influenciaram a adoção do CiRM? 3) Quais 
são os principais elementos e componentes necessários para implementação do CiRM? 4) Quais as dificuldades encontradas no processo de implementação do CiRM? 5) Quais são os resultados esperados ou obtidos com o CiRM? 6) Quais são os pontos considerados fatores de sucesso do CiRM?

Em seguida, foi realizada a análise de conteúdo categorial temática proposta por Bardin (2009), a partir do conteúdo gerado pelas entrevistas. Segundo a autora, trata-se de uma técnica de análise de textos, visando obter, por procedimentos sistemáticos e objetivos de descrição do conteúdo, temas recorrentes que são agrupados para compor uma categoria empiricamente definida, que permita a interpretação de conhecimentos relativos ao objeto da pesquisa. Neste estudo, foi utilizada a análise de conteúdo do tipo indutiva, em que as categorias emergem dos dados (transcrição das entrevistas).

Na etapa seguinte, foram realizadas as análises semântica e de juízes, conforme recomendações de Pasquali (2010) e de Kerlinger e Lee (2008). O objetivo da análise semântica foi verificar se os itens da ERCi eram de fácil compreensão para seu público-alvo e também para dirimir quaisquer dúvidas ou duplicidade de itens. Essa etapa contou com a participação de 22 estudantes da Universidade de Brasília (UnB) em momentos distintos de sua formação acadêmica, variando da graduação até o doutorado. Ao mesmo tempo, foi realizada a análise de juízes que obteve a colaboração de seis pessoas especializadas nas áreas de marketing e de administração pública. O propósito dessa etapa foi verificar a pertinência dos itens em relação aos conceitos de CiRM.

Com os resultados da análise de conteúdo das entrevistas para subsequente elaboração dos itens do instrumento e das validações semântica e de juízes, além da adaptação de alguns itens da escala validada por Demo e Rozzett (2013), por exemplo, substituindo-se o termo "esta empresa" por "o STJ", "cliente" por "cidadão" (um dos itens ficou "O STJ reconhece a importância do cidadão"), foi obtida a versão de aplicação da Escala de Relacionamento com o Cidadão (ERCi), composta por 18 itens considerados pertinentes em relação ao CiRM e claros para o público-alvo ao qual se destinava.

No que tange à etapa quantitativa, a população-alvo foi composta pelo público efetivamente usuário das práticas de CiRM do STJ, a saber, cidadãos que já fizeram uso de algum canal de relacionamento do órgão e também os advogados, considerados pelo STJ uma parte relevante do público que faz uso de seus serviços. Quanto à amostra, ela se caracteriza como não probabilística por conveniência. Em 20 anos de existência, o STJ julgou 3,5 milhões de processos e cada processo possui pelo menos duas partes, além de advogado ou procurador. Assim, de acordo com Cochran (2007), quando a população-alvo tende ao infinito, pode-se fazer uso de amostra não probabilística por conveniência.

O questionário contou com duas versões, a versão física (impressa) e a versão on-line construída na ferramenta Type Form, e a coleta dos dados foi realizada nos meses de novembro e dezembro de 2013. Foram obtidos 217 questionários. Os dados da pesquisa foram então inseridos e tratados no programa SPSS Statistical Package for Social Sciences (pacote estatístico para ciências sociais), versão 18. 
O processo de tratamento dos dados teve como primeira etapa a análise da distribuição de frequência para confirmar a coerência dos dados. O tratamento de dados faltantes (missing values) escolhido foi o listwise deletion, considerado o mais recomendável pelos autores (Pasquali, 2010; Hair et al., 2009), ao retirar da amostra os sujeitos que deixaram algum item em branco. Ao final dessa etapa, restaram 208 questionários. O segundo passo foi a verificação da presença de outliers (valores claramente afastados da média e dos demais valores) pelo método de Mahalonobis (Tabachnick e Fidell, 2012). Então, foram encontrados 3 outliers que foram excluídos da amostra. Destarte, a amostra final contou com 205 questionários, o que é suficiente para atender à condição de 200 sujeitos para rodar a Análise Fatorial Exploratória recomendada por Pasquali (2010) ou à recomendação de Hair e colaboradores (2009) de cinco sujeitos por item na versão de aplicação da escala, no caso de estudos exploratórios; como a versão de aplicação possuía 18 itens, a amostra mínima necessária seria de 90 sujeitos.

Na caracterização da amostra, pouco mais da metade (54\%) é pertencente à faixa etária dos 18 aos 30 anos, a maioria foi composta por homens (52\%) e 62\% dos respondentes foram cidadãos comuns, enquanto $38 \%$ eram advogados. A maior parte da amostra possui ensino superior incompleto (30,2\%) seguido de ensino superior completo $(20,9 \%)$ e o canal de relacionamento mais utilizado foi o virtual (site), com 62\%. Ainda na parte sociodemográfica do questionário, a frequência de uso apontou que 52,7\% dos respondentes se encaixam nas frequências diária, semanal ou mensal e 40,1\% dos respondentes declararam ter suas demandas solucionadas com celeridade e efetividade na maioria das vezes em que utilizaram serviços do STJ.

Por fim, seguindo as recomendações de Hair e colaboradores (2009) e Field (2009), os pressupostos para análise multivariada (no caso, análise dos componentes principais e análise fatorial exploratória) foram testados por meio de gráficos de resíduos e gráficos de probabilidade normal: linearidade do fenômeno, variância constante dos termos de erro (homoscedasticidade) e normalidade da distribuição dos termos de erro. Por fim, as análises de multicolinearidade e singularidade não apresentaram problemas para a amostra pesquisada, ou seja, os valores de tolerance foram superiores a 0,1 e de variance inflation factor (VIF), inferiores a 10,0 (Myers, 1990).

\section{Resultados e discussão}

A análise de conteúdo categorial temática indutiva realizada na parte qualitativa do estudo apontou a existência de duas categorias, tecnologias de atendimento e foco no cidadão, condizentes com os principais pontos abordados na literatura visitada. A escala utilizada foi de concordância do tipo Likert de 5 pontos, variando de discordo totalmente a concordo totalmente e tendo 3 como ponto neutro.

No que tange aos resultados da análise quantitativa, foi realizada a validação psicométrica da escala por meio das análises de componentes principais e fatorial exploratória (AFE). Em primeira instância, foi realizada análise dos componentes principais para verificação da 
viabilidade de se usar análise fatorial (fatorabilidade da matriz e índice de adequação da amostra) e determinação da quantidade de fatores. Para tanto, foram analisados a matriz de correlação e o índice de Kaiser-Meyer-Olkin (KMO). A matriz de correlação confirmou a correlação entre as variáveis com valores significativos, ambos indicando a fatorabilidade da matriz. Os valores das comunalidades também foram altos, mostrando que a matriz é realmente fatorável. Por fim, o cálculo do índice de Kaiser-Meyer-Olkin (KMO) obteve o valor de 0,940, encaixando-se no nível "maravilhoso", conforme critérios de Kaiser (1974).

No que diz respeito à identificação da quantidade de fatores, foram analisados como critérios de escolha os eigenvalues ou autovalores, a porcentagem de variância explicada, o gráfico de screeplot e a análise paralela. O método dos eigenvalues maiores que 1,0 indicou 2 fatores e o de variância total explicada maior que 3\% apontou para 3 fatores. Os três percentuais poderiam ser considerados muito bons, já que qualquer valor acima de $30 \%$ é aceito como razoável para explicar o fenômeno (Pasquali, 2012). A terceira verificação, teste de screeplot, consistiu em uma análise visual do gráfico de autovalores. O teste indicou algo entre 1 e 3 fatores. Vale salientar que esses três métodos podem superestimar o número de fatores que serão extraídos (Pasquali, 2012). Assim, foi feita a análise paralela por ser considerada um dos métodos mais fiéis para a determinação da quantidade de fatores (Hayton et al., 2004). Dessa vez, a análise mostrou que a utilização de um fator seria provavelmente o mais indicado.

A partir dos resultados das análises supracitadas, procedeu-se aos testes de correlação entre os fatores 1, 2 e 3 para se definir finalmente a quantidade de fatores a serem extraídos. Obteve-se alta correlação entre os três fatores, sendo 0,718 a correlação entre os fatores 1 e 2, 0,599 entre os fatores 1 e 3 e 0,612 entre os fatores 2 e 3 . Nesse sentido, partiu-se para a investigação da correlação entre os fatores 1 e 2 . O teste também resultou em um nível alto de correlação de 0,771 e, segundo Pasquali (2012), somente os níveis até 0,3 são os indicados para a extração de mais de um fator, pois fatores muito correlacionados indicam a presença de um fator de segunda ordem, apontando para uma solução unifatorial, corroborando o achado da análise paralela. Dessa forma, considerando que a escala que subsidiou a construção dos itens da ERCi, a saber, a ERC validada por Demo e Rozzett (2013), também é unifatorial e, ainda, que tecnologias de atendimento devem ser desenhadas com foco nas necessidades dos cidadãos (Schellong, 2005), podendo compor um único fator, optou-se pela utilização de apenas um fator como a solução mais adequada para a ERCi.

Com isso, os itens do questionário foram testados em relação à sua validade ou qualidade, confiabilidade e variância total explicada. A validade da escala foi analisada por meio da verificação de suas cargas fatoriais. Esse teste mostra a correlação do item com o fator. Tem-se a classificação das cargas proposta por Comrey e Lee (2013): desprezíveis (menor que 0,3), pobres (igual ou maior a 0,32 e até 0,44 ), razoáveis (igual ou maior a 0,45 e até 0,54 ), boas (igual ou maior a 0,55 e até 0,62), muito boas (igual ou maior a 0,63 e até 0,70) e excelentes (igual ou maior que 0,71). Após quatro iterações, a versão final da ERCi ficou composta por 16 itens, sendo 12 excelentes, 2 muito bons e 2 bons. A tabela 1 apresenta a versão completa da ERCi com os itens e seus respectivos índices psicométricos. 
Tabela 1

Índices psicométricos da versão completa da ERCi

\begin{tabular}{|c|c|c|c|c|}
\hline Item & Descrição & Carga Fatorial & Qualidade & Comunalidade \\
\hline 11 & $\begin{array}{l}\text { Estou satisfeito(a) com a qualidade dos serviços } \\
\text { prestados pelo STJ. }\end{array}$ & ,86 & Excelente & ,77 \\
\hline 2 & O STJ me trata com respeito. & 81 & Excelente &, 72 \\
\hline 8 & $\begin{array}{c}\text { As equipes de atendimento do STJ resolvem meus } \\
\text { problemas. }\end{array}$ &, 81 & Excelente & ,78 \\
\hline 9 & $\begin{array}{l}\text { As equipes de atendimento do STJ são rápidas na } \\
\text { solução dos meus problemas. }\end{array}$ & 80 & Excelente &, 79 \\
\hline 10 & Os atendentes do STJ são atenciosos e prestativos. & ,79 & Excelente & ,66 \\
\hline 14 & O STJ possui um atendimento telefônico eficiente. &, 76 & Excelente &, 64 \\
\hline 3 & O STJ merece minha confiança. &, 74 & Excelente &, 67 \\
\hline 18 & $\begin{array}{l}\text { Recomendo os serviços do STJ para amigos e fami- } \\
\text { liares, caso necessário. }\end{array}$ &, 74 & Excelente & ,60 \\
\hline 1 & O STJ reconhece a importância do cidadão. & ,72 & Excelente &, 57 \\
\hline 12 & $\begin{array}{l}\text { O STJ oferece atendimento personalizado nos seus } \\
\text { canais de relacionamento com os cidadãos. }\end{array}$ & ,71 & Excelente &, 56 \\
\hline 13 & O site do STJ atende as minhas necessidades &, 71 & Excelente &, 56 \\
\hline 4 & $\begin{array}{l}\text { O STJ considera minhas dúvidas, sugestões e recla- } \\
\text { mações. }\end{array}$ &, 71 & Excelente &, 54 \\
\hline 15 & $\begin{array}{l}\text { O STJ possui uma imagem positiva perante a socie- } \\
\text { dade. }\end{array}$ &, 69 & Muito bom &, 59 \\
\hline 16 & O STJ incentiva o exercício da cidadania. & ,68 & Muito bom &, 62 \\
\hline 7 & $\begin{array}{l}\text { O STJ utiliza diferentes canais de atendimento para } \\
\text { facilitar o relacionamento com o cidadão. }\end{array}$ &, 59 & Bom &, 41 \\
\hline 17 & $\begin{array}{c}\text { O STJ possui instalações físicas adequadas para o } \\
\text { atendimento presencial. }\end{array}$ &, 57 & Bom &, 40 \\
\hline Confiabilidade & \multicolumn{4}{|c|}{0,95} \\
\hline $\begin{array}{l}\text { Variância Total } \\
\text { Explicada }\end{array}$ & \multicolumn{4}{|c|}{$53 \%$} \\
\hline
\end{tabular}

Fonte: Elaborada pelos autores.

A partir daí, seguindo a recomendação de Hair e colaboradores (2009) de que as comunalidades devem ser preferencialmente acima de 0,5 para o caso de uma futura validação fatorial confirmatória, apresenta-se ainda uma versão reduzida da ERCi, com 12 itens 
excelentes e índices psicométricos também bastante confiáveis. Considerando a demanda de instrumentos cada vez menores para otimizar a taxa e a confiabilidade de resposta (Saunders, Lewis e Thornhill, 2009), a versão reduzida da ERCi mostrada na tabela 2 é uma boa opção para utilização em pesquisas de diagnóstico e estudos relacionais.

\section{Tabela 2}

Índices psicométricos da versão reduzida da ERCi

\begin{tabular}{|c|c|c|c|c|}
\hline Item & Descrição & Carga Fatorial & Qualidade & Comunalidade \\
\hline 11 & $\begin{array}{l}\text { Estou satisfeito(a) com a qualidade dos serviços } \\
\text { prestados pelo STJ. }\end{array}$ & ,86 & Excelente &, 77 \\
\hline 2 & O STJ me trata com respeito. & 81 & Excelente &, 72 \\
\hline 8 & $\begin{array}{l}\text { As equipes de atendimento do STJ resolvem } \\
\text { meus problemas. }\end{array}$ &, 81 & Excelente & ,78 \\
\hline 9 & $\begin{array}{l}\text { As equipes de atendimento do STJ são rápidas na } \\
\text { solução dos meus problemas. }\end{array}$ &, 80 & Excelente &, 79 \\
\hline 10 & $\begin{array}{l}\text { Os atendentes do STJ são atenciosos e prestati- } \\
\text { vos. }\end{array}$ & ,79 & Excelente & ,66 \\
\hline 14 & O STJ possui um atendimento telefônico eficiente. &, 76 & Excelente &, 64 \\
\hline 3 & O STJ merece minha confiança. &, 74 & Excelente &, 67 \\
\hline 18 & $\begin{array}{l}\text { Recomendo os serviços do STJ para amigos e } \\
\text { familiares, caso necessário. }\end{array}$ &, 74 & Excelente &, 60 \\
\hline 1 & O STJ reconhece a importância do cidadão. &, 72 & Excelente &, 57 \\
\hline 12 & $\begin{array}{l}\text { O STJ oferece atendimento personalizado nos } \\
\text { seus canais de relacionamento com os cidadãos. }\end{array}$ &, 71 & Excelente &, 56 \\
\hline 13 & O site do STJ atende as minhas necessidades &, 71 & Excelente &, 56 \\
\hline 4 & $\begin{array}{c}\text { O STJ considera minhas dúvidas, sugestões e } \\
\text { reclamações. }\end{array}$ & ,71 & Excelente &, 54 \\
\hline Confiabilidade & 0,95 & & & \\
\hline Variância Total & $53 \%$ & & & \\
\hline
\end{tabular}

Fonte: Elaborada pelos autores.

Apesar de os números terem se mostrado bastante satisfatórios, é também preciso analisar a coerência teórica do fator encontrado, a partir da literatura revisada, atestando a validade de conteúdo ou consistência teórica da ERCi (Hair et al., 2009). De fato, todos os 16 itens da ERCi possuem respaldo na literatura, tal qual mostra o quadro 1. 
Quadro 1

Validade de conteúdo da Escala de Relacionamento com o Cidadão (ERCi)

\begin{tabular}{|c|c|c|}
\hline Item & Descrição & Autores \\
\hline 1 & O STJ reconhece a importância do cidadão. & Rozzett e Demo (2010) \\
\hline 2 & O STJ me trata com respeito. & Demo e Rozzett (2013) \\
\hline 3 & O STJ merece minha confiança. & Morgan e Hunt (1994) \\
\hline 4 & O STJ considera minhas dúvidas, sugestões e reclamações. & Morgan e Hunt (1994) \\
\hline 5 & $\begin{array}{l}\text { O STJ utiliza diferentes canais de atendimento para facilitar o } \\
\text { relacionamento com o cidadão. }\end{array}$ & Schellong (2007), Leite e Rezende (2010) \\
\hline 6 & $\begin{array}{l}\text { As equipes de atendimento do STJ resolvem meus proble- } \\
\text { mas. }\end{array}$ & Xavier e Gouveia (2004) \\
\hline 7 & $\begin{array}{l}\text { As equipes de atendimento do STJ são rápidas na solução } \\
\text { dos meus problemas. }\end{array}$ & Xavier e Gouveia (2004) \\
\hline 8 & Os atendentes do STJ são atenciosos e prestativos. & Morgan e Hunt (1994) \\
\hline 9 & $\begin{array}{l}\text { Estou satisfeito(a) com a qualidade dos serviços prestados } \\
\text { pelo STJ. }\end{array}$ & $\begin{array}{l}\text { Rozzett e Demo (2010), Duque, Varajão e Filipe } \\
\text { (2011) }\end{array}$ \\
\hline 10 & $\begin{array}{l}\text { O STJ oferece atendimento personalizado nos seus canais de } \\
\text { relacionamento com os cidadãos. }\end{array}$ & Xavier e Gouveia (2004) \\
\hline 11 & O site do STJ atende as minhas necessidades. & Demo e Ponte (2008) \\
\hline 12 & O STJ possui um atendimento telefônico eficiente. & Demo e Ponte (2008) \\
\hline 13 & O STJ possui uma imagem positiva perante a sociedade. & Fulla (2007) \\
\hline 14 & O STJ incentiva o exercício da cidadania. & Fulla (2007) \\
\hline 15 & $\begin{array}{l}\text { O STJ possui instalações físicas adequadas para o atendimen- } \\
\text { to presencial. }\end{array}$ & Demo e Ponte (2008) \\
\hline 16 & $\begin{array}{l}\text { Recomendo os serviços do STJ para amigos e familiares, caso } \\
\text { necessário. }\end{array}$ & Rozzett e Demo (2010) \\
\hline
\end{tabular}

Fonte: Elaborado pelos autores.

Por fim, foram analisados os resultados referentes à percepção dos cidadãos acerca das iniciativas de CiRM com relação aos aspectos do atendimento, dos canais de relacionamento e da orientação voltada para o próprio cidadão.

De forma geral, a média das respostas ficou em 3,64, o que indica uma percepção dos cidadãos positiva, mas com muito espaço para melhoria (escala de 5 pontos com 5 como ponto máximo e 3 como ponto neutro), acerca das iniciativas de CiRM. Por outro lado, o desvio padrão foi de 1,05, indicando variabilidade ou que os dados não estão tão próximos da média. Ademais, como foi utilizada escala ordinal (tipo Likert) para medir um construto contínuo, buscou-se a moda e a mediana como medidas melhores de tendência central das respostas. O valor mais frequente para moda foi 4 (11 itens), seguido de 3 para cinco itens e o valor 5 para dois itens. Já para mediana, 12 itens apresentaram o valor 4 e seis itens o valor 3. Para escolher os itens com destaque, positivo ou negativo, foi feito o somatório dos percentuais de 
concordo e concordo totalmente (\% CCT) e dos percentuais de discordo e discordo totalmente (\% DDT). Também foi computado o percentual de não concordo, nem discordo (\% NCND). A tabela 3 ilustra esses dados em ordem decrescente de média, ou seja, do item que obteve melhor avaliação para o pior avaliado.

Tabela 3

Visão geral dos resultados acerca da percepção dos cidadãos sobre CiRM no STJ

\begin{tabular}{|c|c|c|c|c|c|c|c|}
\hline Número do Item & Média & Desvio Padrão & Moda & Mediana & $\% \mathrm{CCT}^{*}$ & $\%$ NCND* & $\%$ DDT* \\
\hline 17 & 3,94 & 1,020 & 5 & 4 & 68,8 & 24,4 & 6,8 \\
\hline 7 & 3,91 & 0,914 & 4 & 4 & 71,2 & 22,9 & 5,9 \\
\hline 2 & 3,86 & 1,036 & 5 & 4 & 65,4 & 23,4 & 11,3 \\
\hline 10 & 3,82 & 1,044 & 4 & 4 & 63,4 & 26,8 & 9,8 \\
\hline 16 & 3,80 & 0,994 & 4 & 4 & 67,4 & 22 & 10,6 \\
\hline 1 & 3,75 & 0,962 & 4 & 4 & 66,4 & 23,9 & 9,7 \\
\hline 18 & 3,73 & 1,011 & 4 & 4 & 61,5 & 27,3 & 11,2 \\
\hline 15 & 3,71 & 1,040 & 4 & 4 & 60,5 & 30,2 & 9,3 \\
\hline 13 & 3,70 & 0,953 & 4 & 4 & 64,8 & 23,9 & 11,3 \\
\hline 3 & 3,68 & 1,063 & 4 & 4 & 62,9 & 21,5 & 15,6 \\
\hline 11 & 3,68 & 1,064 & 4 & 4 & 60,5 & 26,3 & 13,2 \\
\hline 5 & 3,64 & 0,983 & 4 & 4 & 59,5 & 28,8 & 11,7 \\
\hline 12 & 3,53 & 0,900 & 3 & 3 & 50,2 & 40 & 9,8 \\
\hline 8 & 3,52 & 1,069 & 3 & 3 & 48,8 & 36,6 & 14,6 \\
\hline 14 & 3,41 & 1,038 & 3 & 3 & 43,9 & 38,6 & 17,5 \\
\hline 9 & 3,40 & 1,132 & 3 & 3 & 43,5 & 38 & 18,5 \\
\hline 4 & 3,32 & 1,063 & 3 & 3 & 41 & 39 & 20 \\
\hline 6 & 3,23 & 1,086 & 4 & 3 & 43,3 & 29,8 & 26,9 \\
\hline
\end{tabular}

Fonte: Elaborada pelos autores.

Os itens que obtiveram os maiores valores de resposta de concordância serão discutidos em detalhes. Os resultados dos itens 7 (O STJ utiliza diferentes canais de atendimento para facilitar o relacionamento com o cidadão), 17 (O STJ possui instalações físicas adequadas para o atendimento presencial) e 13 (O site do STJ atende as minhas necessidades) mostram que os usuários dos serviços do STJ reconhecem a utilização dos variados canais de atendimento e a preocupação do órgão em oferecer uma boa estrutura física e de sistemas para o atendimento ao cidadão.

Os resultado dos itens 16 (O STJ incentiva o exercício da cidadania), 1 (O STJ reconhece a importância do cidadão) e 2 (O STJ me trata com respeito) indicam um bom alinhamento entre o discurso do órgão em ter uma orientação voltada para o cidadão e a percepção do cidadão de verificar isso ocorrendo na prática. 
O resultado do item 4 (O STJ considera minhas dúvidas, sugestões e reclamações) poderia indicar que, apesar de se preocupar em oferecer um bom tratamento para o cidadão, prezando pelo respeito, parece que o STJ não dá ainda a devida importância para ouvir sua opinião, considerando a parcela de $20 \%$ dos respondentes que discordam ou discordam totalmente da questão.

O resultado do item 9 (As equipes de atendimento do STJ são rápidas na solução dos meus problemas) pode indicar que quase $20 \%$ dos cidadãos que necessitam das equipes de atendimento para solucionar alguma demanda não têm celeridade na sua resolução. Todavia, o item 9 também apresentou alta taxa de neutralidade, indicando que possivelmente os respondentes consideraram o tempo de espera para solucionar o problema normal ou nunca tiveram nenhum problema quanto a isso. Observando os resultados do item 8 (As equipes de atendimento do STJ resolvem meus problemas), percebe-se uma pequena diferença na parcela de pessoas que tiveram seu problema solucionado pela equipe de atendimento e também uma diminuição no número de pessoas que discordam ou discordam totalmente. Assim, comparando os dois itens, provavelmente grande parte dos respondentes teve seu problema solucionado, mas não com a rapidez desejada ou mesmo, no contexto do serviço público, não consideram a celeridade na solução de problemas um fator preponderante.

Os resultados dos itens 14 (O STJ possui um atendimento telefônico eficiente) e 6 (Consigo obter as informações em um único local, no STJ, sem precisar ficar me deslocando e/ou não sou transferido(a) várias vezes de um ramal para o outro) mostram taxas mais baixas de neutralidade e mais altas em relação à insatisfação com o canal telefônico e a centralização das informações. Pode servir de indicador para melhorar a efetividade do atendimento telefônico e unificar as informações que possivelmente estão dispersas pelo órgão ou apresentam alguma inconsistência.

Os resultados do item 12 (O STJ oferece atendimento personalizado nos seus canais de relacionamento com os cidadãos) apresentaram uma boa taxa de satisfação, 50\%, com o atendimento personalizado, indicando que boa parte dos usuários já teve algum atendimento customizado. Por outro lado, apresentou grande neutralidade, indicando que parte dos clientes do STJ pode não conhecer as possibilidades do atendimento personalizado.

Os demais itens também apresentaram média acima de 3 e moda 4, o que também confirma a percepção positiva, de maneira geral, quanto às iniciativas do CiRM do STJ.

\section{Conclusões}

Esta seção apresentará uma síntese dos resultados obtidos, as contribuições do estudo bem como suas limitações e uma breve agenda de pesquisas futuras sobre o tema.

A principal contribuição acadêmica deste trabalhado foi a elaboração e validação de uma escala de relacionamento com o cidadão, inédita na literatura nacional e internacional, em duas versões, completa e reduzida, o que preenche uma lacuna na literatura e viabiliza futuros estudos relacionais nas áreas de marketing e administração pública.

Outrossim, a ERCi pode ser usada como ferramenta diagnóstica para os gestores de relacionamento tanto no STJ como em outros órgãos públicos, uma vez que as versões da es- 
cala podem ser adaptadas a outras organizações. Em um momento em que os cidadãos estão exigindo cada vez mais de seus representantes, a adoção da filosofia de CiRM pode ajudar os gestores públicos a entender melhor a percepção dos cidadãos quanto aos serviços prestados, identificando áreas onde melhorias fazem-se necessárias.

Quanto às limitações, a proposta aqui apresentada é uma primeira tentativa de construir e validar uma medida para avaliar iniciativas de CiRM em órgãos da administração pública. Portanto, os resultados são mais indicativos do que conclusivos. Isso somado ao fato de a amostra ser não probabilística, não permitindo qualquer generalização, torna prementes novas validações para que a escala ganhe em confiabilidade e aplicabilidade. Assim, recomenda-se a realização de novos estudos, com amostras maiores em outros órgãos e empresas públicas não só do Poder Judiciário como também dos Poderes Executivo e Legislativo em todas as esferas da administração pública, quais sejam, federal, estadual e municipal, para que uma estrutura conceitual mais abrangente relacionada ao marketing de relacionamento no setor público possa ser desenvolvida no futuro.

Outra limitação do estudo diz respeito ao corte transversal da pesquisa. Nesse sentido, o desenvolvimento de uma base de dados de séries temporais permitirá o teste da estrutura por ora obtida em uma perspectiva longitudinal, o que proporcionará um importante refinamento da escala. Assim, pode haver a necessidade de modificação, inclusão ou mesmo eliminação de alguns dos itens originais da escala de sorte que uma medida sempre atualizada possa ser construída de maneira contínua com base em novas tendências e conceitos da gestão de atendimento aos cidadãos. Interessante também seria testar o modelo unifatorial aqui obtido a partir de análise fatorial confirmatória por meio da modelagem por equações estruturais.

Ainda, a análise da literatura empírica nacional dos últimos cinco anos concernente ao CiRM é inexistente, o que significa um pujante horizonte de possibilidades de investigações científicas dada a relevância atual do tema para a administração pública. E mesmo no que tange ao CRM, recomenda-se a realização de estudos multimétodo que, além das medições das variáveis, possibilitem uma melhor compreensão do que é relevante para uma profícua gestão do relacionamento com os cidadãos.

Por fim, os resultados por ora obtidos não pretendem ser conclusivos, mas representam um primeiro esforço para validar cientificamente uma escala que avalie a percepção dos cidadãos quanto às iniciativas de relacionamento e atendimento dos órgãos públicos. A partir daí, futuras pesquisas podem ser desenvolvidas com base em novas demandas, tendências e cenários da administração pública para que a ERCi possa ser atualizada em uma perspectiva contínua, contribuindo para o avanço progressivo do conhecimento teórico-empírico relativo ao marketing de relacionamento no setor público, onde o principal cliente é o cidadão. 


\section{Referências}

ABRUCIO, Fernando L. O impacto do modelo gerencial na administração pública: um breve estudo sobre a experiência internacional recente. Cadernos Enap, Brasília, n. 10, 1997.

ANTUNES, Joaquim; RITA, Paulo. O marketing relacional como novo paradigma: uma análise conceptual. Revista Portuguesa e Brasileira de Gestão, v. 7, n. 2, p. 36-46, fev./maio 2008.

ARAGÃO, Cecília V. Burocracia, eficiência e modelos de gestão pública: um ensaio. Revista do Serviço Público, Brasília, v. 48, n. 3, p. 105-134, set./dez. 1997.

BATISTA, Luciano. CRM no setor público: potencialidades e desafios. In: CRM na Administração Pública. iGov-Doc., Portugal, v. 14, n. 12, p. 6-10, abr. 2011. Disponível em: <www.espiral-net. com/igovdoc/12/>. Acesso em: 15 abr. 2013.

BARDIN, Laurence. Análise de conteúdo. Lisboa: Edições 70, 2009.

BENOUAKRIM, Hind; EL KANDOUSSI, Fatima. Relationship marketing: literature review. International Journal of Science and Research, v. 2, n. 10, p. 148-152, 2013.

BRESSER-PEREIRA, Luiz C. Da administração pública burocrática à gerencial. Revista do Serviço Público, v. 47, n. 1, p. 58-64, jan./abr. 1996.

COCHRAN, William G. Sampling techniques. 3. ed. Nova York: John Wiley \& Sons, 2007.

COMREY, Andrew L.; LEE, Howard B. A first course in factor analysis. Nova York: Psychology Press, 2013.

DEMO, Gisela. B2C Market: Development of a CRM Scale. In: GHORBANI, Ali (Ed.). Marketing in the cyber era. Hershey, PA: IGI Global, 2014. p. 85-95.

DEMO, Gisela; PONTE, Valter. Marketing de relacionamento (CRM): estado da arte e estudos de casos. Brasília: Atlas, 2008.

DEMO, Gisela; ROZZETT, Késia. Customer relationship management scale for the business-to-consumer market: exploratory and confirmatory validation and models comparison. International Business Research, v. 6, p. 29-42, 2013.

DEMO, Gisela et al. Marketing de relacionamento (CRM): estado da arte, produção nacional na primeira década do milênio e agenda de pesquisa. In: ENCONTRO DA ASSOCIAÇÃO NACIONAL DE PÓS-GRADUAÇÃO E PESQUISA EM ADMINISTRAÇÃO, 35., Rio de Janeiro. Anais... Rio de Janeiro: Anpad, 2011.

DUQUE, Jorge; VARAJÃO, João; FILIPE, Vitor. Implementação de sistemas CRM em municípios portugueses. In: CRM na Administração Pública. iGov-Doc. Portugal, v. 14, n. 12, p. 14-21, abr. 2011. Disponível em: <www.espiral-net.com/igovdoc/12/> Acesso em: 15 abr. 2013.

ERNST, Holger et al. Customer relationship management and company performance: the mediating role of new product performance. Journal of the Academy of Marketing Science, v. 39, n. 2, p. 290-306, 2011. 
FARIA, Luiz Henrique et al. 20 anos de publicações sobre marketing de relacionamento no Brasil: uma análise da produção acadêmica de 1992 a 2012. Revista Brasileira de Marketing, v. 13, n. 1, p. 106-118, 2014.

FERREIRA, Patricia et al. Marketing público e orientação para o cidadão-consumidor: um levantamento da produção científica brasileira entre 1997 e 2008. Gestão Pública: Práticas e Desafios, Recife, v. 3, n. 5, p. 170-195, 2012.

FIELD, Andy. Discovering statistics using SPSS. 3. ed. Londres: Sage, 2009.

FLEURY, Sonia. A seguridade social e os dilemas da inclusão social. Rev. Adm. Pública, v. 39, n. 3, p. 449-469, 2005.

FULLA, Shelley L. The citizen and CRM. In: KAVANAGH, Shayne C. (Ed.). Revolutionizing constituent relationships: the promise of CRM systems for the public sector. Chicago, IL: Government Finance Officers Association, 2007. p. 20-24.

GERZSON, Vera R. S.; MÜLLER, Karla M. Procac/Canoas: comunicação pública e relacionamento com o cidadão. Revista Famecos: Mídia, Cultura e Tecnologia, v. 1, n. 38, p. 62-68, abr. 2009.

GOMES, Adalmir O.; GUIMARÃES, Tomás de A. Desempenho no Judiciário: conceituação, estado da arte e agenda de pesquisa. Rev. Adm. Pública, v. 47, n. 2, p. 379-401, 2013.

GRÖNROOS, Christian. From marketing mix to relationship marketing. Management Decision, v. 32, n. 2, p. 4-20, 1994.

GUPTA, Ashish; SAHU, Ganesh P. A literature review and classification of relationship marketing research. International Journal of Customer Relationship Marketing and Management, v. 3, n. 1, p. 56-81, 2012.

HAIR, Joseph et al. Análise multivariada de dados. 6. ed. Porto Alegre: Bookman, 2009.

HAYTON, James C. et al. Factor retention decisions in exploratory factor analysis: a tutorial on parallel analysis. Organizational Research Methods, v. 7, n. 2, p. 191-205, 2004.

IGLESIAS, Oriol; SAUQUET, Alfons; MONTAÑA, Jordi. The role of corporate culture in relationship marketing. European Journal of Marketing, v. 45, n. 4, p. 631-650, 2011.

KAISER, Henry F. An index of factorial simplicity. Psychometrika, v. 39, n. 1, p. 31-36, 1974.

KERLINGER, Fred N.; LEE, Howard B. Foundations of behavioral research. 5. ed. Independence, KY: Wadsworth Thomson, 2008.

KOTLER, Philip; KELLER, Kevin L. Administração de marketing. 14. ed. São Paulo: Pearson, 2012.

LEITE, Leonardo O.; REZENDE, Denis A. Realizando a Gestão de Relacionamentos com os cidadãos: proposição e avaliação de um modelo baseado no Citizen Relationship Management. Urbe: Revista Brasileira de Gestão Urbana, v. 2, n. 2, p. 247-258, jul./dez. 2010.

MARE. Ministério da Administração e Reforma do Estado. Plano Diretor da Reforma do Aparelho do Estado. Brasília: Presidência da República, Imprensa Oficial, 1995.

MARINI, Caio. Gestão pública: o debate contemporâneo. Salvador: Fundação Luis Eduardo Magalhães - Flem, 2003. 
MIRANDA, Claudia M. C.; ARRUDA, Danielle M. O. A evolução do pensamento de marketing: uma análise do corpo doutrinário acumulado no século XX. Revista Interdisciplinar de Marketing, v. 3, n. 1, p. 40-57, jan./jun. 2004.

MISHRA, Alok; MISHRA, Deepti. Customer Relationship Management: implementation process perspective. Acta Polytechnica Hungarica, v. 6, n. 4, p. 83-99, 2009.

MORGAN, Robert M.; HUNT Shelby D. The commitment-trust theory of relationship marketing. Journal of Marketing, v. 58, p. 20-38, jul. 1994.

MOTTA, Paulo R. A modernização da administração pública brasileira nos últimos 40 anos. Rev. Adm. Pública, v. 41, n. especial, p. 87-96, 2007.

MYERS, Raymond H. Classical and modern regression with applications. Belmont, CA: Duxbury Press, 1990.

NGAI, Eric W. T. Customer relationship management research (1992-2002): an academic literature review and classification. Marketing Intelligence \& Planning, v. 23, n. 6/7, p. 582-605, 2005.

NGAI, Eric W. T.; XIU, Li; CHAU, Dorothy C. K. Application of data mining techniques in customer relationship management: a literature review and classification. Expert Systems with Applications, v. 36, p. 2592-2602, 2009.

NOGUEIRA, José Marcelo et al. Estudo exploratório da eficiência dos tribunais de justiça estaduais brasileiros usando a análise envoltória de dados (DEA). Rev. Adm. Pública, v. 46, n. 5, p. 13171340, 2012.

PASQUALI, Luiz. Análise fatorial para pesquisadores. Laboratório de Pesquisa em Avaliação e Medida (LabPAM) — Instituto de Psicologia. Brasília: Universidade de Brasília, 2012.

PASQUALI, Luiz. Instrumentos psicológicos: manual prático de elaboração. Laboratório de Pesquisa em Avaliação e Medida (LabPAM) — Instituto de Psicologia. Brasília: Universidade de Brasília, 2010.

PAYNE, Adrian. Handbook of CRM: achieving excellence in customer relationship management. Oxford: Elsevier, 2006.

PECI, Alketa et al. Governança e New Public Management: convergências e contradições no contexto brasileiro. Organizações \& Sociedade, Bahia, v. 15, n. 46, p. 39-55, 2008.

PINHO, José A. G. Investigando portais de governo eletrônico de estados no Brasil: muita tecnologia, pouca democracia. Rev. Adm. Pública, Rio de Janeiro, v. 42, n. 3, p. 471-93, 2008.

QUALIS. Consulta Periódicos, 2012. Disponível em <http://qualis.capes.gov.br/webqualis/ConsultaPeriodicos.faces>. Acesso em: 10 out. 2013.

RIBEIRO, Rui. O CRM na AP: relação com o cidadão. In: CRM na administração pública. iGov-Doc. Portugal, v. 14, n. 12, p. 11-13, abr. 2011. Disponível em: <www.espiral-net.com/igovdoc/12/>. Acesso em: 15 abr. 2013.

ROZZETT, Késia; DEMO, Gisela. Desenvolvimento e validação da Escala de Relacionamento com Clientes (ERC). Revista Administração de Empresas, São Paulo, v. 50, n. 4, p. 383-395, out./dez. 2010. 
SAUNDERS, Mark; LEWIS, Phil; THORNHILL, Adrian. Research methods for business students. 5. ed. Londres: FT/Prentice Hall, 2009.

SCHELLONG, Alexander. Citizen relationship management: a study of CRM in government. Peter Lang, 2008. Disponível em: <http://books.google.com.br/books?hl=p$\mathrm{t}-\mathrm{BR} \& \mathrm{lr}=\& \mathrm{id}=7 \mathrm{foDTBvAaUoC} \& \mathrm{oi}=\mathrm{fnd} \& \mathrm{pg}=\mathrm{PR} 9 \& \mathrm{dq}=$ schellong + citizen + relationship + management\&ots $=\_H 5 D 8 V X 0 T 8 \& s i g=A Q 34 M O m q U L k X u 6 L n S t Z O O L 2 p M d g \# v=$ onepage $\& q=s-$ chellong\%20citizen\%20relationship\%20management\&f=false>. Acesso em: 26 maio 2013.

SCHELLONG, Alexander. CRM in the public sector: towards a conceptual research framework. In: PROCEEDINGS OF THE 2005 NATIONAL CONFERENCE ON DIGITAL GOVERNMENT RESEARCH. Digital government society of North America. Atlanta: 2005. p. 326-332.

SCHELLONG, Alexander; LANGENBERG, Thomas. Managing citizen relationships in disasters: Hurricane Wilma, 311 and Miami-Dade County. In: HICSS 2007. ANNUAL HAWAII INTERNATIONAL CONFERENCE, 40 ${ }^{\mathrm{TH}}$, 2007, Havaí. System sciences. Havaí: IEEE, 2007. p. 96-96.

SENA, Gabriel A.; SILVA, Edson A.; LUQUINI, Roberto de A. A reforma do Poder Judiciário no Brasil: uma análise a partir do modelo gerencial. Revista de Ciências da Administração, Florianópolis, v. 4, n. 16, p. 68-78, 2012.

SHETH, Jagdish N.; PARVATIYAR, Atul. Evolving relationship marketing into a discipline. Journal of Relationship Marketing, v. 1, n. 1, p. 3-16, 2002.

SOJAN, Simi; RAPHY, Sify K.; THOMAS, Pinky. Techniques used in decision support system for CRM - a review. International Journal of Information Technology Infrastructure, v. 3, n. 1, p. 9-12, 2014.

TABACHNICK, Barbara G.; FIDELL, Linda S. Using multivariate statistics. 6. ed. Boston: Pearson Allyn And Bacon, 2012.

WAHLBERG, Olof et al. Trends, topics and under-researched areas in CRM research: a literature review. International Journal of Public Information Systems, Sundsvall, v. 3, p. 191-208, 2009.

XAVIER, Jorge; GOUVEIA, Luis B. O relacionamento com o cidadão: a importância do território, 2004. In: CONFERENCIA IBERO-AMERICANA. Disponível em: <www2.ufp.pt/ lmbg/com/xavier_iadisibero04.pdf > . Acesso em: 15 maio 2013.

XAVIER, Jorge; GOUVEIA, Luis B.; GOUVEIA, Joaquim B. A gestão do relacionamento com o cidadão em cidades e regiões digitais. In: CONFERÊNCIA IADIS IBERO-AMERICANA WWW/INTERNET, 2003, Algarve. Anais... Algarve: Iadis, 2003. p. 125-132.

Gisela Demo tem pós-doutorado em Management \& Organizations (University of California, Los Angeles), doutora em psicologia organizacional pela Universidade de Brasília (UnB) e professora do Departamento de Administração e do Programa de Pós-Graduação em Administração da UnB. E-mail: giselademo@ unb.br.

Renata Pessôa é bacharel em administração pela Universidade de Brasília (UnB). E-mail: renatinhaunb -adm@yahoo.com.br. 